\title{
Evolutionary Profile of Severe Acute Ulcerative Colitis in Chronic Inflammatory Bowel Diseases
}

\author{
Hakima Abid, Fatima Babakhouya, Ihssane Mellouki, Mounia El Yousfi, Noureddine Aqodad, \\ Dafr Allah Benajah, Adil Ibrahimi, Mohamed El Abkari
}

Hepatogastroenterology Department, Hassan II University Hospital of Fez, Univesity Sidi Mohamed Ben Abdellah, Fez, Morocco

Email: abidhakima@hotmail.com

How to cite this paper: Abid, H., Babakhouya, F., Mellouki, I., El Yousfi, M., Aqodad, N., Benajah, D.A., Ibrahimi, A. and El Abkari, M. (2018) Evolutionary Profile of Severe Acute Ulcerative Colitis in Chronic Inflammatory Bowel Diseases. Open Journal of Gastroenterology, 8, 107-117. https://doi.org/10.4236/ojgas.2018.83012

Received: January 16, 2018

Accepted: March 27, 2018

Published: March 30, 2018

Copyright $\odot 2018$ by authors and Scientific Research Publishing Inc. This work is licensed under the Creative Commons Attribution International License (CC BY 4.0).

http://creativecommons.org/licenses/by/4.0/

\begin{abstract}
Background: Severe acute colitis is a common complication of inflammatory bowel disease (IBD). Their diagnosis is based on clinical, laboratory, endoscopic and radiological. The severe acute colitis is a medical and surgical emergency; its mortality is $1 \%$ to $3 \%$. The management should be swift and coordinated, upon admission, between medical and surgical teams. Methods: This is a retrospective study in Gastroenterology Service at the University Hospital HASSAN II Fez, over a period of 10 years (2005-2015). We included all patients admitted for severe acute colitis; all the epidemiological, clinical, endoscopic, histological, and therapeutic monitoring of patients were collected. Results: We collected 123 patients. Their average age was 35 years (16 - 70). It was a female predominance (sex ratio $\mathrm{F} / \mathrm{M}=1.19$ ). 54 patients were admitted for an inaugural severe acute colitis (43\%), while 69 patients were known carriers of IBD (56\%). All patients were admitted to an array of severe acute colitis according to the criteria of Truelove and Witts modified. 9 patients were operated urgently because there was the presence of complications ( 5 cases of perforation, 3 cases of massive rectal bleeding, and one patient with an abscess in the right iliac fossa). Corticosteroids intravenously was administered to 114 patients, 74 patients (64\%) had remission. Patients who have not responded to corticosteroids IV $(\mathrm{N}=40)$ : 1) 12 patients received treatment with oral cyclosporine: the remission rate was 66\%. 2) 8 patients were put under Infliximab: The response rate was 75\%. 3) Patients who have not responded to a second-line treatment underwent subtotal colectomy with a dual stoma. 4) The surgery was indicated as a second-line treatment in 20 patients who all received a subtotal colectomy with double stoma; totalizing colectomy and ileoanale anastomosis ware made in 4 patients. The mortality rate is higher in our series (12\%) mainly postoperatively; it is due to the delayed admission of patients, which promotes the development of complications. Conclusion: Acute Severe Ulcerative Colitis is a medical and surgical emergency
\end{abstract}


that requires a multidisciplinary approach; medical treatment is the basis of initial treatment; but surgery must always be indicated at the right time avoiding increasing the death rate, this rate is important in our series.

\section{Keywords}

Acute Severe Ulcerative Colitis, Infliximab, Cyclosporine, Colectomy

\section{Introduction}

Severe acute colitis (SAC) is a classic complication of ulcerative colitis (UC) that can be life-threatening in the short term. This anatomo-clinical entity can also be observed during Crohn's disease (CD) or infectious colitis. The diagnosis is based on the association of clinical and biological criteria and can be supported by morphological criteria (endoscopy, imaging). SAC is a medical and surgical emergency whose mortality according to the literature is $1 \%$ to $3 \%$ [1] [2] [3]. Its management must be fast and coordinated, from the admission of the patient, between medical and surgical teams.

\section{Materials and Methods}

We carried out a retrospective study of 123 patients admitted for severe acute colitis in gastro-enterology department of Hassan II University Hospital of Fez over a period of 10 years (2005-2015). We included in this study all cases of severe acute colitis retained on the clinical-biological criteria of Truelove and Witts modified.

All epidemiological, clinical, endoscopic, histological and therapeutic data as well as patient follow-up were collected.

\section{Results}

During the study period, we collected 123 patients with an average age of 35 [16 - 70], with a slight female predominance (sex ratio $F / M=1.19$ ). Fifty four patients were admitted for an inaugural severe acute colitis (43\%), while 69 patients were already known to have IBD (56\%): 56 patients with UC (45\%), 10 patients with Crohn's disease (8\%) while 3 patients (2\%) with IBD not yet determined.

For previous treatments in known patients with IBD: 20 patients were on mesalamine, 12 patients on Salazopurine, 7 patients on Azathioprine, 3 patients on 6-Mercaptopurine, 20 patients on oral corticosteroids, 5 patients on mesalamine enema, and 2 patients under corticosteroid enema.

The mean duration of disease progression before the flare was 30 months [4 240 months]. All patients were admitted to SAC (Truelove and Modified Wittz score) with average score of Lichtiger at 12 (11 - 14). The average onset of symptomatology was 15 days earlier in our patients (10 - 20). On admission, a 
radiograph of the Abdomen without preparation (ASP) was performed in all patients: No case of colectasia was found, but the presence of pneumoperitoneum was objectified in 3 patients who carried out a CT scan confirming the presence of colonic perforation in these 3 patients. Biologically, the average level of CRP was $84(23-370)$, the mean hemoglobin level was $7.4 \mathrm{~g} / \mathrm{dl}(2.7-14)$ with an average albumin level of $19 \mathrm{~g} / \mathrm{l}(13$ - 38). Stool coproparasitology was requested for all patients. It found pathogenic forms of amoebiasis in 8 patients, Shiguella infection in 2 patients, while it was negative for the rest of the patients. Initial rectosigmoidoscopy was performed in all patients except for the 3 patients with perforation; it objectified the presence of signs of endoscopic gravity in $47 \mathrm{pa}$ tients (38\%) while 73 patients hadn't endoscopic signs of severe disease activity.

Systematic biopsies were made for the pathological study and for the search for certain pathogenic germs whose CMV was positive in 2 patients. Surgery was indicated immediately (before any drug treatment) in 9 patients presenting a complication upon admission:

- Peritonitis with perforation in 5 patients.

- massive rectal bleeding in 3 patients.

- Abscess of the right iliac fossa with a luminal disease flare in one single patient.

All these patients underwent subtotal colectomy with double stoma; the post-operative history in these patients was marked:

- By mortality of 6 patients:

- 5 were admitted for colonic peritonitis by colonic perforation and who have set up a septic shock in the immediate postoperative history.

- One patient admitted for massive rectal bleeding with hemodynamic instability and hemorrhagic shock)

- By a good evolution in the 3 remaining patients.

Regarding first-line medical treatment, 114 patients were first treated with intravenous corticosteroid at a dose of $0.8-1 \mathrm{mg} / \mathrm{kg} /$ day; heparin therapy was routinely administered in all patients because of the risk of thromboembolism in severe acute colitis, metronidazole was also administered systematically in all patients since Morocco is an endemic country with amoebiasis. The daily clinical-biological monitoring, based on the evaluation of the Lichtiger score, showed a good evolution under intravenous corticosteroid in the seventh day in 74 patients (64\%) hence the use of oral corticosteroid, a gradual decline in corticosteroid . was started in these patients after clinical remission.

For patients who failed to respond to intravenous corticosteroid $(\mathrm{N}=40)$, the use of second-line treatment was indicated:

- Oral ciclosporin was used in 12 patients: The oral form was administered at a dose of $4 \mathrm{mg} / \mathrm{kg} /$ day (Injectable ciclosporin not available in Morocco) with the aim of achieving ciclosporinemia of 150 to $250 \mathrm{ng} / \mathrm{ml}$, Lipid and magnesium supplementation has been done with strict biologic monitoring to watch for side effects that are well known for this treatment. A favorable 
clinical response was observed in 8 patients (66\%) while 4 patients (34\%) had failed oral ciclosporin, hence surgery with subtotal colectomy with double stoma. For patients with a good response to oral ciclosporin, an immunosuppressive therapy based on thiopurines was started (knowing that 7 patients were naive to thiopurines) with good clinical and biological evolution.

After approximately 2 years of evolution, only one patient (8\%) presented a second episode with failed medical treatment, hence the use of subtotal colectomy.

- Infliximab was used in 8 patients with an induction regimen $(5 \mathrm{mg} / \mathrm{kg} / \mathrm{day}$ at w0, w2 and w6) followed by maintenance treatment ( $5 \mathrm{mg} / \mathrm{kg} /$ day every 8 weeks) for patients having responded to induction therapy. A clinical response was observed in 6 patients (75\%) whereas a failure in Infliximab was observed in one patient. In one patient, we noted the onset of a severe systemic infection obliging to stop the continuation of Infliximab. For these last 2 patients, a subtotal colectomy with double stoma was performed. Only one patient died from septic shock secondary to febrile pancytopenia after treatment with Infliximab.

- Surgery was indicated as second-line treatment in 20 patients because of the unavailability of second-line medical treatment.

- A preparation for surgery was done first in intensive care unit.

- Subtotal colectomy by laparotomy was performed for all these patients with double stoma within an average of 12 days (5 -21 days); The sigmoidostomy allowed to clean the remaining colon post-operatively;

- Postoperative follow-up was marked by:

- The appearance of peritonitis in 5 patients with $100 \%$ mortality due to septic shock despite surgical revision;

- One case of mortality of massive pulmonary embolism.

- Simple post operative follow-up in 14 patients.

- Nearly $80 \%$ of histologic examinations of the colectomy specimens concluded to ulcerative colitis, while it was non-specific acute colitis in $20 \%$ ( $\mathrm{n}=$ 4).

- Only 4 of our patients benefited from a secondary intervention with proctectomy and ileoanal anastomosis on J reservoir, of whom 3 patients presented stenosis of the colo-anal anastomosis afterwards (after about 3 months of anastomosis). These patients have benefited from several anal dilation sessions with good evolution.

- The subsequent evolution after an initial remission of 4 patients (after approximately 1 year) was marked by the installation of luminal flare revealing their Crohn's disease which was initially considered as an ulcerative colitis UC.

In total, we have a high mortality rate of $12 \%$ (15 patients):

- 12 patients who died post-operatively,

- 2 patients who died of complications during their hospitalizations despite a clinical remission of their flare (pulmonary embolism and septic shock), 
- 1 patient died from septic shock secondary to pancytopenia after treatment by Infliximab.

The evolutionary profile of our patients is summarized in Figure 1.

Statistical analysis of our study showed that hemoglobin levels less than 10 $\mathrm{g} / \mathrm{dl}$, severe hypo albuminemia and the presence of signs of endoscopic severity are predictive factors for failure of intravenous corticosteroid and recourse to a second-line treatment (Table 1).

\section{Discussion}

Severe acute colitis (SAC) is a complication of chronic inflammatory bowel disease that can complicate RCH or Crohn's disease as well as other forms of colitis (infectious, ischemic or medicated) [1]. A CAG can initiate the disease in about $1 / 3$ of the cases, or it can complicate an already known IBD; In our series the severe flare was inaugural in $43 \%$ of patients. The introduction of corticosteroids in the 1950s significantly reduced the mortality rate for acute severe colitis from $30 \%-60 \%$ to less than $1 \%$, and since then, corticosteroids have been considered the first-line treatment for severe flare of IBD [2]. However, the rate of response

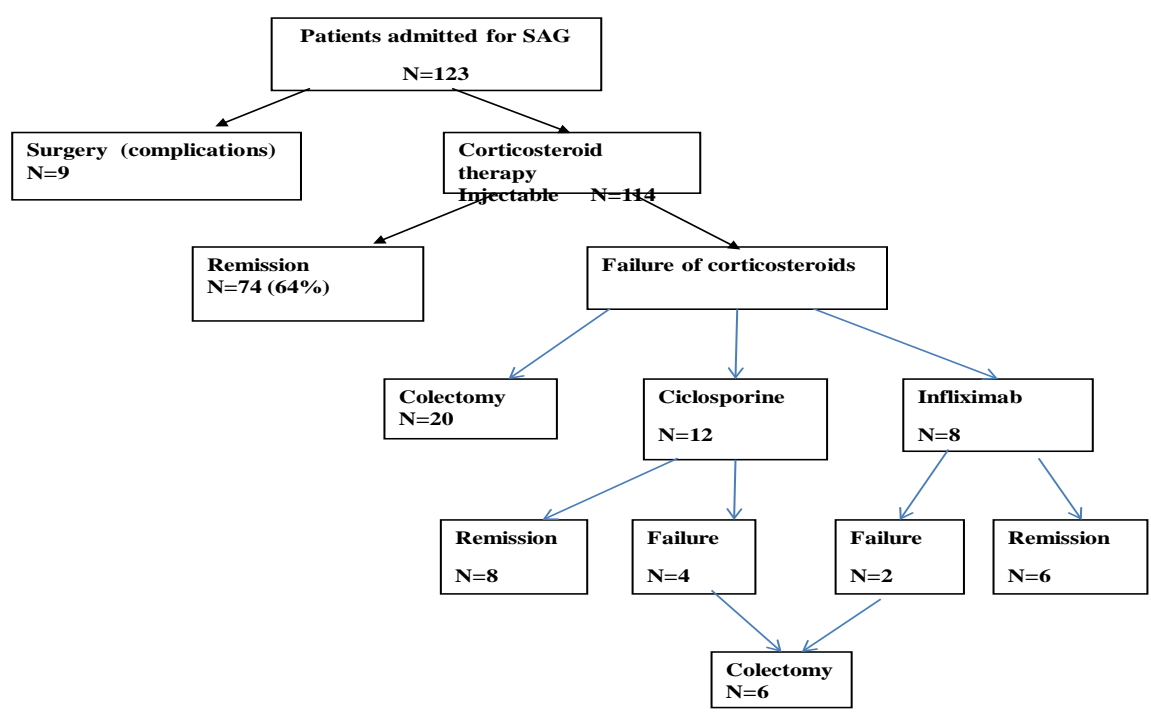

Figure 1. Evolutionary profile of severe acute colitis in our series.

Table 1. Risk factors for failure of injectable corticosteroid therapy in our series.

\begin{tabular}{cccc}
\hline The variables & $\begin{array}{c}\text { Response to corticosteroid } \\
\text { therapy }\end{array}$ & second ligne therapy & $P$ \\
\hline middle age (years) & 35 & 34 & 0.9 \\
Sex & $63 \%$ & $36,7 \%$ & 0.61 \\
- man & $69 \%$ & $31 \%$ & \\
- woman & $32 \%$ & $48 \%$ & $\underline{\mathbf{0 . 0 4 8}}$ \\
Anemia $<$ 10 g/dl & $8,6 \%$ & $40 \%$ & $\underline{\mathbf{0 . 0 0 1}}$ \\
severe Hypoalbuminemie & $36,2 \%$ & $64 \%$ & $\underline{\mathbf{0 . 0 1 9}}$ \\
endoscopic gravity signs & & & \\
\hline
\end{tabular}


to intravenous corticosteroids has not changed over the years, with up to $30 \%$ $40 \%$ of patients presenting with an inadequate response to treatment [3]. The first prognostic studies [4] [5] looked for the parameters associated with the need for a colectomy and they led to the implementation of the clinical and biological parameters for this decision. Thus, a high stool number, the persistence of high levels of CRP, the persistence of rectal bleeding after three days of intravenous corticosteroids have become simple criteria for the introduction of rescue therapies such as ciclosporin or Infliximab. Using similar criteria for clinical response, two prospective studies [4] [6] and two retrospective studies [5] [7] reported an initial efficacy of intravenous corticosteroids of $40 \%-57 \%$. In the long-term follow-up of patients with severe acute colitis, Bojic et al. reported that patients who had a partial response after 7 days of intravenous corticosteroid had a significantly higher cumulative probability of colectomy in follow-up than those who achieved early clinical remission [8]. Colectomy should not be considered as the last recourse in case of failure of drug treatments, but also as a therapeutic option discussed at each stage of the management of a SAC. This is a treatment that has reduced SAC mortality, provided it is not proposed too late. Colectomy is indicated as an emergency in cases of perforation, toxic megacolon, massive rectal bleeding or multi-visceral failure [9]. These complications have become less common since the early management of severe inflammatory colitis. They concern 7\% of our series. A UK Oxford study in 2009 by Dinesen et al. about 750 patients reported a colectomy rate in patients who were admitted once or more for severe acute colitis as much as $40 \%(74 / 186)$ compared to only $3 \%$ (19/564) among those who have never been admitted for severe flare. The overall colectomy rate was $12 \%$ [10]; In this British cohort, these results are similar to $10.4 \%$ reported in study in Northern Europe in 2007 [11], but lower than that reported in a US study by Kaplan et al. where a colectomy rate cumulative $27 \%$ has been reported [12]. A study by kumar et al. in 2015 looked at the effect of early colectomy (in the first 7 days) in case of failure of the intravenous corticosteroid on the postoperative mortality rate; the results showed that the postoperative mortality was $1.1 \%$, significantly lower than the mortality observed in cases of colectomy beyond 7 days $(15.6 \%, p=0.006)$ [13]. Although intravenous corticosteroids are the basis of medical treatment, approximately $30 \%$ to $40 \%$ of patients are resistant to steroid treatment. In the past, when other drug treatments were unavailable for corticosteroid-refractory SACs, the only option was emergency colectomy, which resulted in about $10 \%$ of the mortality rate 3 months after surgery. Recently, ciclosporin and Infliximab have shown both their ability to have certain benefits for patients with severe acute colitis resistant to intravenous corticosteroid therapy. However, since 2005, several placebo-controlled randomized clinical trials have demonstrated that Infliximab is safe and effective in SAC refractory to intravenous corticosteroid with $60 \%$ to $80 \%$ remission in the short term by avoiding colectomy rates [14]. A meta-analysis of 34 studies on Infliximab found a mean short-term response and 
remission of $68 \%$ and $40 \%$, respectively, and an average long-term response and remission of 53\% and 39\%, respectively [15]. A Belgian study done in 2014 grouped 285 patients with acute severe corticosteroid colitis who were put on infliximab; $61 \%$ of patients had a relapse and $20 \%$ had a colectomy. Clinical response and mucosal healing are independent predictors of short-term relapse-free survival; while independent predictors of survival without colectomy were mucosal healing, clinical remission, and albumin above $35 \mathrm{~g} / \mathrm{l}$. Infliximab serum levels greater than $2.5 \mathrm{mg} / \mathrm{ml}$ at week 14 of treatment predicted survival without recurrence $(P<0.001)$ and survival without colectomy $(P=0.034)[16]$. Monterubbianesi et al. reported in a study involving 113 patients admitted to 11 Italian centers treated with Infliximab (induction therapy: S0, S2, S6) that colectomy rates at 3 and 12 months were 18.6\%. (95\% CI 11.8\% - 26.9\%) and $25.6 \%$ (95\% CI 17.9\% - 34.7\%) respectively. High CRP values and severe endoscopic lesions were associated with the risk of colectomy at 12, 24, 36 by $91 \%$, $85 \%, 81 \%$ respectively, whereas signs of endoscopic severity were the only predictor of long-term colectomy ( $R R=7.0,95 \%$ CI 1.09 to 44.7) [17]. Since 1994, through several controlled and uncontrolled clinical trials, intravenous ciclosporin has been shown to be effective in severe acute colitis with a response rate who can reach $64 \%$ to $82 \%$. However, ciclosporin has been associated with a high risk of long-term colectomy ( $88 \%$ colectomy rate at 7 years). In addition, a significant risk of toxicity and side effects as well as monitoring have limited its use in clinical practice [18]; Conventionally, ciclosporin is administered by continuous intravenous infusion at the dose of $2 \mathrm{mg} / \mathrm{kg}$ per day, with the objective of ciclosporinemia effective between 150 and $250 \mathrm{ng} / \mathrm{ml}$. In case of response to intravenous treatment, a relay by oral ciclosporin is then undertaken. Some teams proposed out of hand oral micro-emulsion treatment with ciclosporin $\left(\mathrm{Neoral}^{\circ}\right)$, at an initial dose of $2 \mathrm{mg} / \mathrm{kg}$ per 12 hours and the objective of a circulating residual rate around $100 \mathrm{ng} / \mathrm{ml}$ and a peak (2 hours after taking the drug) close to $600 \mathrm{ng} / \mathrm{ml}$ [19] [20]. In our study ciclosporin was administered orally given the unavailability of the intravenous form in Morocco with an initial response rate of $66 \%$ which is concord with the results of the literature. Currently, some guidelines recommend intravenous ciclosporin or Infliximab as rescue therapy for patients with severe acute colitis resistant to intravenous corticosteroid therapy.

A recent meta-analysis of six retrospective cohort-type studies comparing the clinical result of patients with SAC corticoresistant receiving Infliximab or ciclosporin as a rescue therapy showed no significant difference in colectomy rate at 3 months and 12 months, in the adverse effects, and in postoperative complications between the two groups [21].

In addition, the first prospective randomized controlled trial comparing the efficacy of ciclosporin versus Infliximab, recently published in Europe, demonstrated that there is no significant difference in treatment result between the two groups [22]. 
Although there has been several data comparing the efficacy of intravenous ciclosporin with Infliximab, there is still debate about which drug is more effective in severe acute colitis refractory to corticosteroids [23] [24].

A study by Kim et al. compared the efficiency of ciclosporin and infliximab in corticoresistant CAG: No difference between infliximab and ciclosporin compared to colectomy prevention was noted. However, infliximab with azathioprine may be more effective than ciclosporin alone to avoid colectomy [25].

Table 2 compares the results of our study with those of a recent Spanish study done in 2016 involving 62 patients with severe acute colitis [26]; it shows a high rate of colectomy in our series compared to the Spanish series, and this is due to the unsatisfactory availability of second-line medical treatment which impose us to recourse to colectomy frequently (Table 2).

A recent study conducted in 2016 assessed the short-term colectomy rate and mortality for severe acute colitis over the last 40 years (1976 to 2010) in 159 patients in 4 cohorts; cohort 1: (1976-1980); cohort 2 (1986-1990); cohort 3 (1996-2000); cohort 4 (2006-2010). The colectomy rate was $64.7 \%, 62.0 \%, 44.4 \%$ and $9.8 \%$, respectively, in the four cohorts $(p<0.0001)$ and the mortality rate decreased by $8.8 \%$ in cohort 1 , at 0 in cohort $4(p=0.04)$ [27].

The operative mortality of subtotal colectomy is null or close to $1 \%$ in the absence of complication, but it increases considerably, especially if there is colonic perforation, Thus, in one series, the operative mortality was less than $1 \%$, whereas $25 \%$ of the patients had complicated forms (hemorrhage, perforation, colectasia) [28]. Preoperative mortality for patients operated on peritonitis was $100 \%$ in our series. On the other hand the mortality remains very high in our series even in the absence of peritonitis since it is $12 \%$. We impute this abnormally high rate of mortality to late arrival of patients within our hospital.

Table 2. Comparison of the results of our study with the results of a recent Spanish study.

\begin{tabular}{lcc}
\hline & $\begin{array}{c}\text { Spanish study [26] } \\
\mathrm{N}=62\end{array}$ & $\begin{array}{c}\text { Our study } \\
\mathrm{N}=123\end{array}$ \\
\hline Response to corticotherapy & $31(50 \%)$ & $74(60 \%)$ \\
Reponse to second line medical treament & $27(43 \%)$ & $12(9 \%)$ \\
- Infliximab & 14 & 6 \\
- Ciclosporine & 10 & 8 \\
- both & 03 & $35(28 \%)$ \\
Surgery: & $5(6.5 \%)$ & 9 \\
Immediatly & 1 & 26
\end{tabular}




\section{Conclusion}

SAC is a medical and surgical emergency requiring multidisciplinary approach. The initial treatment is based on intravenous corticosteroid, followed in case of failure by ciclosporin or Infliximab. However, colectomy should still be considered a standard treatment for SAC and not a last recourse solution in case of failure of drug treatments given the risk of mortality which is $1 \%$ to $3 \%$ but which is even higher in our series (12\%), therefore it is essential to confide the patient to the surgeon at the right time to avoid both an early and abusive surgery or to operate an already complicated patient.

\section{Conflicts of Interest}

The authors don't declare any conflict of interest.

\section{Contributions of the Authors}

Hakima Abid; Fatima Babakhouya, Ihssane Mellouki, Mounia El yousfi, Noureddine Aqodad, Dafr Allah Benajah, Adil Ibrahimi, Mohamed El Abkari.

\section{References}

[1] Jewell, D., et al. (1991) Indications and Timing of Surgery for Severe Ulcerative Colitis. Gastroenterology International, 4, 161-164.

[2] Dignass, A., Lindsay, J., Sturm, A., et al. (2012) Second European Evidence-Based Consensus on the Diagnosis and Management of Ulcerative Colitis. Part 2: Current Management. Journal of Crohn's and Colitis, 6, 991-1030. https://doi.org/10.1016/j.crohns.2012.09.002

[3] Turner, D., Walsh, C.M., Steinhart, A.H. and Griffiths, A.M. (2007) Response to Corticosteroids in Severe Ulcerative Colitis: A Systematic Review of the Literature and Meta-Regression. Clinical Gastroenterology and Hepatology, 5, 103-110. https://doi.org/10.1016/j.cgh.2006.09.033

[4] Travis, S.P., Farrant, J.M., Ricketts, C., et al. (1996) Predicting Outcome in Severe Ulcerative Colitis. Gut, 38, 905-910. https://doi.org/10.1136/gut.38.6.905

[5] Carbonnel, F., Gargouri, D., Lémann, M., et al. (2000) Predictive Factors of Outcome of Intensive Intravenous Treatment for Attacks of Ulcerative Colitis. Alimentary Pharmacology and Therapeutics, 14, 273-279. https://doi.org/10.1046/j.1365-2036.2000.00705.x

[6] Benazzato, L., D’Inca, R., Grigoletto, F., et al. (2004) Prognosis of Severe Attacks in Ulcerative Colitis: Effect of Intensive Medical Treatment. Digestive and Liver Disease, 36, 461-466. https://doi.org/10.1016/j.dld.2003.12.017

[7] Daperno, M., Sostegni, R., Scaglione, N., et al. (2004) Outcome of a Conservative Approach in Severe Ulcerative Colitis. Digestive and Liver Disease, 36, 21-28. https://doi.org/10.1016/j.dld.2003.04.001

[8] Manosa, M., Cabré, E., Garcia-Planella, E., et al. (2011) Decision Tree for Early Introduction of Rescue Therapy in Active Ulcerative Colitis Treated with Steroids. Inflammatory Bowel Diseases, 17, 2497-2502. https://doi.org/10.1002/ibd.21634

[9] Gan, S.I. and Beck, P.L. (2003) A New Look at Toxic Megacolon: An Update and Review of Incidence, Etiology, Pathogenesis, and Management. American Journal of Gastroenterology, 98, 2363-2371. https://doi.org/10.1111/j.1572-0241.2003.07696.x 
[10] Dinesen, L.C., Walsh, A.J., Protic, M.N., et al. (2010) The Pattern and Outcome of Acute Severe Colitis. Journal of Crohn's and Colitis, 4, 431-437. https://doi.org/10.1016/j.crohns.2010.02.001

[11] Hoie, O., Wolters, F., Riss, L., Bernklev, T., Aamodt, G., Clofent, J., et al. (2007) Low Colectomy Rates in Ulcerative Colitis in an Unselected European Cohort Followed for 10 Years. Gastroenterology, 132, 507-515. https://doi.org/10.1053/j.gastro.2006.11.015

[12] Kaplan, G.G., McCarthy, E.P., Ayanian, J.Z., Korzenik, J., Hodin, R. and Sands, B.E. (2008) Impact of Hospital Volume on Postoperative Morbidity and Mortality Following a Colectomy for Ulcerative Colitis. Gastroenterology, 134, 680-687. https://doi.org/10.1053/j.gastro.2008.01.004

[13] Saha, S.K., Kumar, A., Panwar, R., et al. (2015) Early Colectomy in Steroid-Refractory Acute Severe Ulcerative Colitis Improves Operative Outcome. Apollo Medicine, 12, S25. https://doi.org/10.1016/j.apme.2015.11.073

[14] Seo, H.I., Park, D.I., Kim, T.O., et al. (2014) The Effect of Infliximab on Patients with Ulcerative Colitis in Korea. Intestinal Research, 12, 214-220.

https://doi.org/10.5217/ir.2014.12.3.214

[15] Gisbert, J.P., Gonzalez-Lama, Y. and Mate, J. (2007) Systematic Review: Infliximab Therapy in Ulcerative Colitis. Alimentary Pharmacology \& Therapeutics, 25, 19-37. https://doi.org/10.1111/j.1365-2036.2006.03131.x

[16] Arias, M.T., Casteele, N.V., Vermeire, S., et al. (2015) A Panel to Predict Long-Term Outcome of Infliximab Therapy for Patients with Ulcerative Colitis. Clinical Gastroenterology and Hepatology, 13, 531-538. https://doi.org/10.1016/j.cgh.2014.07.055

[17] Monterubbianesi, R., Aratari, A., Armuzzi, A., et al. (2014) Infliximab Three-Dose Induction Regimen in Severe Corticosteroid-Refractory Ulcerative Colitis: Early and Late Outcome and Predictors of Colectomy. Journal of Crohn's and Colitis, 8, 852-858. https://doi.org/10.1016/j.crohns.2014.01.006

[18] Creed, T.J. and Probert, C.S. (2007) Review Article: Steroid Resistance in Inflammatory Bowel Disease-Mechanisms and Therapeutic Strategies. Alimentary Pharmacology \& Therapeutics, 25, 111-122. https://doi.org/10.1111/j.1365-2036.2006.03156.x

[19] de Saussure, P., Soravia, C., Morel, P. and Hadengue, A. (2005) Low-Dose Oral Microemulsion Ciclosporin for Severe, Refractory Ulcerative Colitis. Alimentary Pharmacology \& Therapeutics, 22, 203-208. https://doi.org/10.1111/j.1365-2036.2005.02552.x

[20] Weber, A., Fein, F., Koch, S., Dupont-Gossart, A.C., Mantion, G., Heyd, B., et al. (2006) Treatment of Ulcerative Colitis Refractory to Steroid Therapy by Microemulsion Cyclosporine (Neoral). Inflammatory Bowel Diseases, 12, 1131-1135. https://doi.org/10.1097/01.mib.0000235096.78736.8e

[21] Chang, K.H., Burke, J.P. and Coffey, J.C. (2013) Infliximab versus Cyclosporine as Rescue Therapy in Acute Severe Steroid-Refractory Ulcerative Colitis: A Systematic Review and Meta-Analysis. International Journal of Colorectal Disease, 28, 287-293. https://doi.org/10.1007/s00384-012-1602-8

[22] Laharie, D., Bourreille, A., Branche, J., et al. (2012) Ciclosporin versus Infliximab in Patients with Severe Ulcerative Colitis Refractory to Intravenous Steroids: A Parallel, Open-Label Randomised Controlled Trial. The Lancet, 380, 1909-1915. https://doi.org/10.1016/S0140-6736(12)61084-8

[23] Sjöberg, M., Walch, A., Meshkat, M., et al. (2012) Infliximab or Cyclosporine as 
Rescue Therapy in Hospitalized Patients with Steroid-Refractory Ulcerative Colitis: A Retrospective Observational Study. Inflammatory Bowel Diseases, 18, 212-218. https://doi.org/10.1002/ibd.21680

[24] Croft, A., Walsh, A., Doecke, J., Cooley, R., Howlett, M. and Radford-Smith, G. (2013) Outcomes of Salvage Therapy for Steroid-Refractory Acute Severe Ulcerative Colitis: Ciclosporin vs. Infliximab. Alimentary Pharmacology \& Therapeutics, 38 , 294-302. https://doi.org/10.1111/apt.12375

[25] Kim, E.H., Kim, D.H., Park, S.J., et al. (2015) Infliximab versus Cyclosporine Treatment for Severe Corticosteroid-Refractory Ulcerative Colitis: A Korean, Retrospective, Single Center Study. Gut and Liver, 9, 601-606. https://doi.org/10.5009/gnl14120

[26] Llaó, J., Naves, J.E., Ruiz-Cerulla, A., et al. (2016) Improved Outcome of Acute Severe Ulcerative Colitis While Using Early Predictors of Corticosteroid Failure and Rescue Therapies. Digestive and Liver Disease, 48, 608-612.

https://doi.org/10.1016/j.dld.2016.02.024

[27] Clementa, V., Aratari, A., Papi, C. and Vernia, P. (2016) Short Term Colectomy Rate and Mortality for Severe Ulcerative Colitis in the Last 40 Years. Has Something Changed? Digestive and Liver Disease, 48, 371-375.

https://doi.org/10.1016/j.dld.2015.12.014

[28] Alves, A. (2003) Traitement d'une colite aiguë grave compliquant une maladie inflammatoire chronique de l'intestin. American College of Surgeons, 197, 3-9. 